\title{
The Present Situations of Dragon and Lion Dancing in Universities and Strategies for Its Development
}

\author{
Xin CHEN \& Liang LIU* \\ Hubei Engineering University, Hubei, China
}

\begin{abstract}
The paper starts with the current situation of the loong dance and the lion dance in Chinese colleges and universities, followed by a specific analysis of the sports in such schools. It continues to analyze the elements of its talent training, choices of teachers' books, student recruiting mechanism and institutional management which have exercised a great impact on the development of the provincial sports. The paper concludes with some suggested countermeasure for its better development in colleges and universities and for achieving the goal of "Lion Dance Entrance into Colleges and Universities" laid down by the Administration Center of Social Physical Education.
\end{abstract}

KEYWORD: the loong dance and the lion dance; current situation; countermeasure

\section{RESEARCH PURPOSE AND METHODS}

\subsection{Research Purpose}

By investigating the present situation of Dragon and Lion Dancing in some universities, analyzing the factors affecting its development and the countermeasures, this paper aims at providing a theoretical basis for the popularity of Dragon and Lion Dancing in more universities.

\subsection{Research Methods}

\subsubsection{Documentation}

Collect and go through related documents, and then organize, summarize and analyze them.

\subsubsection{Logical Analysis}

By using the methods of induction, deduction, analogy and comprehensive logical analysis, this paper explores the related information and appraises the relevant conclusions and recommendations.

\section{CONCLUSIONS AND ANALYSIS}

\subsection{The Present Situation of Dragon and Lion Dancing in Universities}

The targeted data collection shows that there has been a rapid development of offering the courses on Dragon and Lion Dancing in Chinese universities. In 1998, Hunan Normal University created the first university dragon dancing team in China. In 2001, Dragon and Lion Dancing became a compulsory course for students majored in martial arts in Beijing Sport University.[1] After that Dragon and Lion Dancing ushered in its climax in Chinese universities. Today, more than one hundred universities have their own school dragon teams. Some universities mastering higher skills of Dragon and Lion Dancing even offer coach training, theory courses, practical courses, technology observing courses and drumming practice courses for this sport.

\subsection{Inevitable Trend of Dragon and Lion Dancing Going into PE Classes in Universities}

\subsubsection{Market Demand for Sports Talents}

Dragon and Lion Dancing is part of Chinese traditional culture and an indispensable part of gala celebration. The sport not only helps students understand better the rich connotation of our traditional culture, enhances their senses of national pride and patriotism, mobilizes their enthusiasm of study, promotes their physical and mental health, but also cultivates professionals in need for the market. It is a need for the discipline construction and an inevitability of the times.

\subsubsection{Requirements for Deepening Education Reform in Universities}

Physical Education reform has been speeding up in 
Chinese universities. The traditional PE teaching mode and assessment system will gradually be different. The new mode of option teaching brings opportunities and vitality for Dragon and Lion Dancing in universities' PE classes. Although Dragon and Lion Dancing is a collective sport and still stays at an exploring stage, in the long run its characteristics of nationality, performance, entertainment, aesthetics, body building and education will attract students. It is inevitable that Dragon and Lion Dancing goes into PE classes and becomes one of students' option courses.

\subsection{Restricting Factors in Development of Dragon and Lion Dancing}

\subsubsection{Restricting Factors from Professional Talents}

Though Dragon and Lion Dancing has a long history in China, it lacks professional training. Most dragon and lion dancers do not major in this sport, instead, most of them major in martial arts or other specialties. They do not have good skills and then need professional training and enhancement. However, the shortness of talents in teaching and training makes Dragon and Lion Dancing difficult to develop.

\subsubsection{Restricting Factors from Admission Policy}

While many universities enroll students nationwide, there are some drawbacks in admission policy which work against the cultivation of Dragon and Lion Dancing reserves. The requirements for the examination paper scores limit many high-level athletes to choose universities. Currently, most universities do not have fixed partners in cultivating Dragon and Lion Dancing talents; many universities cannot well finish the succession, resulting in temporary shortage of professional talents. Those factors restrict the overall improvement of the dancing teams and greatly hinder its orderly development in universities.[2]

\subsubsection{Restricting Factors from School Leaders' Attention}

From the point of view of university's internal management, some major leaders' management is incompatible with the rapid development of the times. They are backward in management ideas, methods, means and conceptions, which make them think it would take too much money and effort to carry out Dragon and Lion Dancing. Then they exclude the sport from physical education teaching list. They do not want to make investment in venues and equipment for the sport, and do not want to send out teachers to get trained either. The neglect from major leaders makes Dragon and Lion Dancing difficult to develop in a healthy direction and greatly block its booming in universities.

\subsection{Strategies for Dragon and Lion Dancing in Universities}

\subsubsection{Combination of Popularization and Improvement}

Popularization is an important work for the development of Dragon and Lion Dancing. Without popularization, it will be impossible to form a wide range of sports activities, and will be impossible to play the Dragon and Lion Dancing's social function as a symbol of the Chinese nation. In order to make the folk Dragon and Lion Dancing more impressive and more vigorous, and in order to get more people know about Dragon and Lion Dancing and take part into it, on the one hand, we should publicize the sport through the media, on the other hand, we should take advantage of nation traditional physical education curriculum reform and introduce the sport into the universities' PE classes. We also need to improve the teaching of Dragon and Lion Dancing as well as combine the spiritual civilization with the quality education. Relying on its popularity in universities we can achieve the purpose of national fitness and promote its popularity and development nationwide. To improve on the basis of the popularity is not only the need of the sport's development, but also the wish of descendants of the Dragon.

\subsubsection{Combination of Inheritance and Development}

We can see from the history of Dragon and Lion Dancing that the sport always develops and innovates itself along with the Chinese history. In this new era, the innovation means we should combine its improvement with the spirit of the times and the market economy. The dancing should adapt to the new situations to achieve its development in the market. However, the innovation is not to mechanically apply the integrative pattern of competitive sports, it is not a simple regression to the ancient Dragon and Lion Dancing either. In the process of reform and development, the innovation should emphasize the unity of the dancing's selfmaintaining and self-renewal, which means to achieve the unity of tradition and modern, and the unity of nation and the globe.

\subsubsection{Combination of Fitness and Entertainment}

Sports not only entertain ourselves but also entertain others. Both athletes and spectators are able to have fun, regulate their emotions and uplift their spirit through sports. Sports strive to meet people's spiritual and cultural needs, which are the psychological trend of the people all over the world. Dragon and Lion Dancing first presents us the appearance of the dragon and the lion, so a beautiful shape is the foundation of the dancing. The shapes of the dragon and the lion should be verisimilar, 
looking like a dragon or a lion. And the shapes should meet most people's sense of beauty, demonstrated as a vigorous, energetic dragon or lion. In modern society, the better material life gives people more leisure time, and sports gradually play an important role at people's leisure time. However, the traditional sports should have higher value on entertainment and fitness if they want to be accepted by the public. Therefore, Dragon and Lion Dancing should explore harder on its value of entertainment and fitness in its future reform and development, trying to use its wonderfully intense performances and competitions to enliven festive occasions and bring happiness for life.

\subsubsection{Rely on the Society, Take a Market-oriented and Society-oriented Way}

Dragon and Lion Dancing, as a good carrier for business and cultural exchanges, will enter the market and become more popular. Clubs can be organized for Dragon and Lion Dancing to open up its competition market. Enhancing the competition level and strengthening the commercial packing will develop its competition market.[3] Market rules should be taken advantage of to diversify the competition forms and socialize the funding sources. If we want a rapid development of Dragon and Lion Dancing, we have to accelerate its process of socialization. The purpose of socialization is to expand its mass base. Only on the basis of abundant fans can we develop and socialize the dancing. On the one hand, we should break ethnic and regional limitations, letting the dancing of one certain area or one certain ethnic group perform all over the country to extend its scope and scale. On the other hand, we should popularize and vulgarize the Dragon and Lion Dancing. Only in this way can we greatly mobilize the public to participate in the activity and flourish our outstanding culture.

\section{CONCLUSIONS}

3.1 Universities should do more work on the construction of Dragon and Lion Dancing curriculum, for Dragon and Lion Dancing has farreaching significance in broadening professional caliber, inheriting traditional culture, richening cultural and recreational life on campus, enhancing athletic skill, and meeting social demands and student's needs on employment.

3.2 As a new traditional sport in universities, Dragon and Lion Dancing is not well equipped in time in many aspects like teaching content, teaching materials, teachers, venues, devices, money, etc.
That leads to the slow development, disordered teaching and poor teaching quality of Dragon and Lion Dancing.

\section{SUGGESTIONS}

4.1 Using the enhancement of the sports culture on campus as a breakthrough point, let's vigorously propagate the traditional culture of Dragon and Lion Dancing. We should have more people know the dancing, improve its influence in universities, take care of the equipment and construct the venues for it. In short, we should create favorable material conditions for Dragon and Lion Dancing.

4.2 Scientifically manage Dragon and Lion Dancing in universities by perfecting management system and setting up Dragon and Lion Dancing associations. In order to make the dancing keep growing in universities, we should make full use of universities' advantages in human resources, researching, funding, information, cultures and so on, trying to make universities be the spreading base of Dragon and Lion Dancing.

4.3 Strengthen the conception of curriculum and gradually popularize the courses of Dragon and Lion Dancing in universities. Formulate the curriculum standard for Dragon and Lion Dancing as soon as possible. Compile text books of Dragon and Lion Dancing for common universities. Pay more attention to the teaching reform such as heuristic teaching, combination of theory with practice, and combination of in-class with after-class.

4.4 Dragon and Lion Dancing also should proactively return to the society. It can take advantage of market rules to diversify its competition forms and socialize its funding sources. In this way it can achieve "nurturing dragons by dragons, nurturing lions by lions", a virtuous circle of sustainable development.

\section{REFERENCES}

[1] He Jin, Liu Yongfeng. A Study on the Current Situation of the Loong Dance and the Lion Dance in Jiangsu Colleges and Universities and Suggestions for Its Development Countermeasure. Journal of Jilin Institute of Physical Education. 2008 (5):86-87.

[2] Cao Longfei. On the Value of Dragon and Lion Dances in Colleges. Wushu Science. 2013(10):103-104.

[3] ZHOU Wen-yan. Analysis on the value of establishing the course of performing dragons and lions to regular institution. Journal of Yichun University .2007(4):79-80. 